\title{
The Value of Metacognitive Control Training in Enhancing Moroccan EFL Learners' Reading Process in Tertiary Education
}

\author{
Mohammed Msaddek (Corresponding author) \\ Department of English Language \& Literature, Faculty of Letters and Human Sciences- \\ Mohammedia, Hassan II University, Casablanca, Morocco
}

Received: September 29, 2020 Accepted: December 2, 2020 Published: December 6, 2020

doi:10.5296/ijele.v9i1.18041 URL: https://doi.org/10.5296/ijele.v9i1.18041

\begin{abstract}
The present study, drawing on a quasi-experimental design, is geared towards probing into the value of the delivery of metacognitive control training in improving English as a foreign language (EFL) learners' performance in textual reading at the university level. To investigate this issue at length, two EFL first-semester groups majoring in English studies were selected as the main respondents. The treatment group trained in metacognitive control consists of sixty-three ( $n=63)$ students and the non-treatment group receiving no training is comprised of fifty $(n=50)$ students. These two groups were presented with both a narrative and an expository reading text at the pre- and post-intervention phase along the continuum of the semester (Semester One) and were administered a 'self-report questionnaire' at each phase. The findings feature that the treatment group reflected a more significant measure of improvement in terms of the executive and metacognitive control exercised during the reading process than the non-treatment group did. Thus, the study puts forward the implied view that metacognitive control instruction with regard to reading comprehension is to be embedded in the university curriculum for the optimization of the learners' reading process.
\end{abstract}

Keywords: Executive control, metacognition, metacognitive control, metacognitive training, reading strategies 


\section{Introduction}

The correlation existing between the metacognitive theory, as a new area of cognitive psychology, and reading has earned intense interest among many researchers (e.g., Smith \& Dauer, 1984; Casanave, 1988; Jiménez, et al., 1996; Griffith \& Ruan, 2005; Li, 2010; Pei, 2014; Boyraz \& Altinsoy, 2017). In effect, it can be plainly admitted that the cognitive engagement in the reading process is governed, in large part, by metacognitive thinking and strategic regulation which the overall literature considers as crucial variables in the meaning-construction process (Brown, 1981; Garner, 1987; Paris \& Paris, 2001; Tonks \& Taboada, 2011; Maftoon \& Tasnimi, 2014). Thinking metacognitively and critically while attempting to develop efficient sense of any given textual content implies methodical recourse to metacognitive control strategies on the part of learners. These metacognitive strategic moves, if used in a coordinated manner, can guarantee a great measure of efficacy at the level of both comprehension achievement and reading performance.

A large body of previous research substantiated the plain value of metacognitive intervention in optimizing the reading process among learners. In this context, whereas some instructional interventions focused on the instruction of self-questioning (André \& Anderson, 1978-79; Janssen, 2002), schemata construction/ question generation (Singer \& Donlan, 1982), and meaning inferring (Kern, 1989; Hall, 2016), other interventions addressed such techniques as paraphrasing (Lauterbach \& Bender, 1995), semantic mapping/ experience-text-relationship (Carrell, et al., 1989) and note-taking (Rahmani \& Sadeghi, 2011). Further, other reading scholars undertook interventions on think-aloud (Bauman, Seifert-Kessel, \& Jones, 1992; Boulware-Gooden, et al., 2007), comprehension monitoring (Bereiter \& Bird, 1985; Casanave, 1988), goal-setting (Johnson, Graham, \& Harris, 1997), and self-regulation/ self-control (Short \& Ryan, 1984; Maftoon \& Tasnimi, 2014; Morshedian, Hemmati, \& Sotoudehnama, 2017). These specific reading-related intervention research studies, among others, brought about concrete, positive results at the level of reading performance amongst the target learners and confirmed the viability and efficiency of strategy instruction in the improvement of academic textual reading.

Actually, in most of these above-stated strategy training studies aiming at reinforcing the learners' reading potential in an effective fashion, it is found that whilst the subjects under the treatment condition were instructed in a single reading strategy, other subjects received training in only some, but not all, the basic strategies which fall within the overall landscape of metacognitive and executive control. This, indeed, cannot allow learners, in a way or another, to develop the complete ability to adopt self-regulated and self-directed reading behavior as a key contributor to the meaning construction procedure. Further, some studies (Maftoon \& Tasnimi, 2014; Morshedian, et al., 2017) focused on self-regulation/ self-control instruction in textual reading without addressing the variable of text genre (i.e., narrative, expository). Taking account of this state of affairs, the current study attempts to put to test the applied value of the process of providing Moroccan EFL university learners with a comprehensive instruction in metacognitive control strategies (planning, monitoring, and evaluating) in approaching various text genres (i.e., narrative, expository). 


\section{Review of Related Literature}

\subsection{Metacognition: A Brief Overview}

The concept of metacognition was initiated in educational and psychological research by Flavell (1971) who directed his research endeavors towards the study of human memory and thinking processes. It is a form of self-regulation that facilitates the act of monitoring and controlling cognitive performance (Rahimi \& Abedi, 2015). Indeed, metacognition denotes critical awareness of the cognitive processes required for performing academic tasks (e.g., reading, writing, listening). As noted by many researchers (Brown, 1980; Hill \& Hannaffin, 1997; Lawrence, 2007; Hogan, Dwyer, Harney, Noone, \& Conway, 2015) whose research interest is nested within the cognitive theory, metacognition is strongly correlated with cognition. This shows that metacognition constitutes an efficient approach applied for assessing one's cognitive knowledge and abilities with regard to reading performance.

According to Brown (1980), metacognition is conceptualized as "the deliberate conscious control of one's own cognitive actions" in undertaking the reading task. It occupies a crucial part in enabling readers to be entirely aware of the process of understanding written texts by applying the effectual strategies that constitute the basic footsteps towards accomplishing the textual comprehension. In a similar way, Dewitz, Carr, and Patberg (1987) state that metacognition refers to the readers' awareness of their level or degree of understanding and their ability to regulate the process of comprehension as they proceed through texts (p.111). This clearly shows that, by involving themselves in a sophisticated kind of metacognitive thinking, readers will be able to conduct, direct and guide their reading process with greater effectiveness and utter facility.

Thus, the fundamental link relating metacognition and the reading process, as two essential constructs, is expressly manifest in various aspects which are incarnated in planning, monitoring and evaluating that are involved in textual reading. These strategies, reflecting the metacognitive nature of reading and the substantial amount of the learners' awareness of text processing, explicitly reveal the underlying premise that metacognitive thinking plays a critical role in assisting the learners to approach reading texts with much greater efficiency and success. Obviously, an effective comprehension of the text requires and depends on the aforementioned metacognitive processess which are addressed in the following sub-sections.

\section{A. Planning:}

As an efficient metacognitive strategy enabling learners to organize the way of conducting a studying task, planning is a solid foundation upon which the process of reading is strongly based (Msaddek, 2016). This strategy refers to "the cognitive processes that function to control information processing or task performance from the outset" (Schmitt \& Newby, 1986, p.30). It is the initial step that university students, as mature, capable learners, are expected to take in order to facilitate the process of coping with a given learning task. It is through planning that learners tend to determine the goals related to the task and select the promising strategies that have to be implemented to achieve an adequate understanding. In effect, as it constitutes an underlying strategy that entails a great amount of metacognitive 
thinking, planning is "goal-related" (Schmitt \& Newby, 1986). It is at this stage that learners decide to take the appropriate pathway through which they can diligently approach the learning task.

\section{B. Monitoring:}

Monitoring, as a 'regulatory' learning strategy, refers to “one's awareness of comprehension and task performance while in the process of performing a specific task" (Nietfeld, Cao, \& Osborne, 2005, p.9). It is, indeed, another essential metacognitive strategy which enables learners to be fully aware of the process of understanding. In other terms, monitoring, when undertaking a given reading task, gives learners the opportunity to ensure that the process of comprehension is effectively undertaken. For Nietfeld et al. (2005), who basically underscore the critical significance of the monitoring strategy in dealing with different studying tasks, effective monitoring "aids students in keeping track of ongoing cognitive processes and using regulatory strategies to solve problems" (p.9).

\section{Evaluating:}

Evaluating can be defined as an effectual medium of assessing the process of learning. It refers to "appraising the products and regulatory processes of one's learning" (Schraw \& Moshman, 1995, p. 355). In fact, as a basic metacognitive strategy, evaluating is a sophisticated kind of critical thinking since it allows learners to know the extent to which their understanding of the academic task is entirely attained. Further, by evaluating their conducted learning process, EFL learners can identify their major weaknesses and strengths in that they can examine the efficiency of the implemented strategies and improve their way of approaching and coping with the subsequent studying tasks. This manifests that the evaluation act can be conceived of as the most paramount strategy via which the learners critically reflect upon and metacognitively rethink their assimilation and understanding of the different academic tasks. It assists them to measure the extent to which their mastery of the content of the material under focus is achieved.

Clearly, planning, monitoring, and evaluating remain the potent footsteps in the process of EFL reading since they allow learners to handle a range of reading tasks in a seemingly effectual and organized way. In fact, it can be assumed that executing the reading process requires that learners direct, regulate and control the use of strategies in order to reach the meaning.

\subsection{The Role of Executive Control in the Reading Process}

Executive control is conceptualized as an efficient, feasible method of organizing, directing and controlling any given learning/ reading act. For many researchers (e.g., Garner, 1987; Fernandez-Duque et al., 2000), executive control and metacognition are interrelated as they presuppose sophisticated, effective strategy use for regulating cognitive performance. This showcases that executive control, entailing a vast amount of high-level thinking and rationality, incorporates three key strategies which can be referred to as planning, monitoring and evaluating. Actually, the execution of these stated metacognitive strategies entails 
self-control, critical thinking, and rational reasoning for achieving an efficiency-driven sort of comprehension during the process of reading.

To further elaborate upon the concept of executive control, Sternberg (1984) sets forth a broad host of executive processes that really constitute the backbone of analyzing and interpreting information. They are inextricably related to the processes of planning, monitoring and evaluating which can be starkly manifested in what follows: (a) deciding on the nature of the problem, (b) deciding on the performance components relevant for solving tasks, (c) deciding how strategically to combine performance components, (d) selecting a mental representation for information, (e) allocating resources for problem solution, (f) monitoring solution processes, and (g) being sensitive to external feedback (Sternberg, 1984). These processes of executive control can be viewed as contributing factors for assisting learners to fully conceive and process the information included in the various learning tasks. In fact, Sternberg (1984) tends to associate these stated processes with the intelligence of the learner. In this respect, it can be declared that "executive control is the aptitude" (Gaskins et al., 2007, p. 213) by means of which learners conduct their reading process more effectively and properly.

Hence, it is reasonable to confirm that executive control is part and parcel of metacognition. They both involve similar aspects that typically characterize the processes of undertaking learning tasks. As noted by Shimamura (2000), "both metacognitive control and executive control share the primary feature of enabling top-down modulation of cognitive processes" (p.315). This common point between metacognition and executive control is markedly obvious in their great emphasis on the effective analysis and synthesis of the learning and reading tasks. Moreover, Garner (1987) states that both metacognition and executive control stress the strategies used by learners (e.g., cognitive, metacognitive). However, it can be declared that, whereas research on metacognition focuses on the cognitive knowledge of any learning endeavour, research on executive control highlights the control reflected by learners for any task performance (Cavanaugh \& Perlmutter, 1982).

In essence, executive control occupies a major part in enabling EFL learners to opt for the effective strategies for achieving an adequate understanding of the content of a given written discourse. This shows that executive control is a key prerequisite to the conduct of any academic undertaking. It is considered as an optimal method of regulating and guiding the process of analyzing information in a more potentially successful, perfect manner.

\subsection{Self-control/ Self-regulation Training}

Self-control involves using strategies and taking control of the learning process. It is used interchangeably with the concept of self-regulation in the domain of metacognitive theory (Zimmerman, 1990; Wenden, 1991). Training in self-control reflects the metacognitive as well as the executive aspects that characterize the learning act in all its forms and manifestations. In fact, the approach of self-control/ self-regulation training is intended to initiate learners into the overall knowledge of self-regulatory strategies needed for the execution of academic tasks. Thus, without the possession of solid awareness of the characteristics of the cognitive learning/reading activity and the potent techniques that can 
facilitate effective comprehension, learners cannot develop and advance their cognitive abilities. In this regard, Boekaerts (1999) maintains that self-regulated learning is predicated on the selection, combination, and coordination of strategies in an effective manner. This reveals that self-control, as a self-regulatory procedure, can increase the learners' potential in coping with a diversity of academic written discourse.

Obviously, self-control training procedures instruct students explicitly how to monitor and evaluate their performance (Paris et al., 1986, p.106). It is an efficient instructional method that encourages learners to think critically and metacognitively while attempting to approach a particular reading text. Put differently, this type of instruction helps to develop the readers' ability to plan the course of the reading process, monitor their ongoing comprehension and assess the extent to which an adequate understanding of the text is achieved. This reflects that self-control, as an effectual technique of regulating and orienting one's cognitive performance in textual reading, necessitates a certain measure of awareness of the strategies that should be used in seeking text understanding. In this view, Wenden (1991) states that:

Providing students with training in self-regulation (also referred to as self-control training) increases the likelihood of strategy maintenance and transfer commonly acknowledged measures of the success of any kind of skill training. In the absence of this type of self-control training, learners will not become autonomous in their use of strategies and will remain dependent on their teachers. (p.106)

In effect, self-control/ self-regulation training was operated by many leading researchers (e,g., Short \& Ryan,1984; Maftoon \& Tasnimi, 2014). For instance, in an attempt to enhance less skilled readers' comprehension of written texts, Short and Ryan (1984) conducted self-control training. They assigned the learners with a narrative text (story) and encouraged them to raise a set of wh-questions while being engaged in the reading process. The findings indicate that self-control instruction can increasingly improve the process of understanding, namely among less skilled readers. Another training study undertaken by Maftoon and Tasnimi (2014) features the significant effect of the inclusion of self-regulation/ self-control in the instruction of the reading process to EFL learners. The latter were exposed to a wide range of self-regulatory strategies (i.e., organizing, planning, monitoring, information seeking, self-evaluation) and manifested tangible reading improvement.

More importantly, a grouping of educational researchers (Butler, Cartier, Schenllert, Gagnon, \& Giammarino, 2011; Maftoon \& Tasnimi, 2014; Roohani \& Asiabani, 2015; Morshedian, et al., 2017) strongly advocate the perceived usefulness and efficacy of the adoption of self-regulated/ self-controlled reading in academic contexts as it results in enhanced, competent kind of textual reading among the learners. This provides evidence that self-regulated/ self-controlled reading is a functional determinant of successful achievement at the level of reading comprehension.

Thus, the purposeful delivery of self-control/ self-regulation training in metacognitive reading processes (e.g., planning, monitoring, and evaluating) can be a proper, optimal technique in strengthening the learners' cognitive capability and enabling them to use the 
strategies more frequently in processing the different written texts. Noteworthy is the premise that the learners, being exposed to this kind of self-control instruction, can develop the metacognitive knowledge pertaining to deeper textual analysis in potentially differing ways. This is the focal goal orientating the conduct of this research study.

\section{Research Questions \& Hypotheses}

The experimental study under scrutiny probes into the worth of the delivery of metacognitive training in improving EFL learners' metacognitive control in textual reading. For the fulfillment of this objective, three research instruments were implemented to elicit insightful, rich data. These instruments include a set of selected reading comprehension texts (narrative $\&$ expository), a 'self-report questionnaire', and strategy training. Thus, two research questions directing this research study have been formulated:

a- Do Moroccan EFL university learners make use of metacognitive control strategies?

b- To what extent does metacognitive control training enhance Moroccan EFL university learners' strategic reading behavior?

In light of these stated research questions, two main hypotheses have been put forward for the conduct of a rigorous kind of data analysis.

1-Moroccan EFL university learners do not utilize the metacognitive control strategies for processing academic written texts more frequently.

2-Metacognitive control training can enhance Moroccan EFL university learners' strategic reading behavior.

\section{Method}

\subsection{Participants}

One hundred and thirteen (113) Moroccan EFL university students belonging to the English language department at the Faculty of Letters and Human Sciences, Mohammed V- Agdal in Rabat were the main respondents for the current study. The two groups were randomly selected and the gender issue was not controlled. One group consisting of sixty-three $(n=63)$ students, was trained in using metacognitive control strategies and the other group, including fifty $(n=50)$ students, received no training in these strategies. Both groups were assigned two reading comprehension texts (i.e., narrative, expository) at the pre- and post-intervention stage along the course of the semester (Semester One).

\subsection{Instrumentation}

The instruments implemented in this quasi-experimental study included reading texts (narrative \& expository), a 'self-report questionnaire', and metacognitive control training. By using these data collection instruments, the study adopts a qualitative and quantitative approach for conducting thorough investigation of the research topic at issue. In effect, the prime impetus for the assignment of the pre- and post-intervention reading texts is to ensure whether the process of training the target subjects (the experimental group) in making efficient use of metacognitive control strategies (e.g., planning, monitoring, and evaluating) 
can have any potential impact on the EFL learners' strategic behavior and reading capabilities. In other words, the use of the pre- and post-treatment reading texts (i.e., narrative, expository) can reveal the degree to which the undertaken training in metacognitive control is of great significance. Obviously, the two reading comprehension texts (narrative \& expository) of the pre- as well as the post-treatment, which were operated throughout this experimental study, are seemingly identical in format and are manifestly comparable, to some extent, at the linguistic level, length and the nature of the comprehension questions.

As to the 'self-report questionnaire', it was used for the sake of obtaining insights pertaining to the EFL learners' strategic reading behavior. It is an effective technique of eliciting data on the major mental mechanisms and metacognitive processes that learners engage in to synthesize the text input. Therefore, the adoption of this kind of questionnaire, which was administered to the target subjects both before and after the conducted experimental treatment, derives from the basic premise that it is a certain measurement tool that substantially provides thorough insights into the strategies employed in EFL text processing (e.g., Anani Sarab \& Reihani, 2010; Shellings, 2011) as it gives an overall overview of how the strategic reading moves (e.g., planning, monitoring, and evaluating) are conducted and effected by EFL learners. In addition to exploring the 'heuristic' processes utilized by the target learners, the operated questionnaire is intended to measure the extent to which metacognitive control strategies can be acquired by the experimental subjects through the strategy training as compared to the control group which was not initiated into any intervention.

The ultimate aim of the training in metacognitive control, which is a key part of this quasi-experimental study, is to provide Moroccan EFL university students with the underlying metacognitive strategic moves used in text processing and meaning analysis. The treatment group, targeted in this case study, was exposed to the process of practising and applying the focused control strategies in analyzing and approaching written discourse (e.g., narrative, expository) for the whole semester (Semester One). Essentially, given the marked premise that most learners inadequately use metacognitive reading strategies, the training in metacognitive control is intended to equip the experimental EFL learners with planning, monitoring and evaluating strategies. The main rationale for the adoption of this kind of training is that it can aid the subjects to strengthen their knowledge pertaining to diverse metacognitive control strategies (e.g., planning, monitoring, evaluating), initiate them into the operation of practising the taught strategies and help them foster the potential of applying them more independently (e.g., Jones et al., 1987; Pressley, 2000; Maftoon \& Tasnimi, 2014; Morshedian et al., 2017).

\subsection{Procedure}

Both the experimental and the control groups, at the pre-intervention level, were exposed to two reading texts (narrative and expository) which include four major tasks (wh-questions, meaning inferring, paraphrasing, and summary writing). Upon finishing the reading procedure and providing the responses, they were required to fill out the 'self-report questionnaire' with a view to tapping into the metacognitive control strategies that they utilized in the course of processing and developing sense of the textual content. Of course, 
this questionnaire can provide clear insights into the learners' reading strategic steps.

The conducted training in metacognitive control, which was received by the experimental EFL subjects, lasted for a semester-long period. Each instructional intervention session was allotted three hours per week. Notably, throughout the training sessions (14 sessions), a series of reading comprehension texts (narrative \& expository) was assigned to the EFL group under investigation and effectively studied in an attempt to enable the actual applicability of the instructed metacognitive control strategies. Further, this can allow the target EFL learners to call upon and put into actual practice all the taught strategies (e.g., planning, monitoring, and evaluating) that can guarantee an in-depth analysis and full comprehension of the content, and thus advance and promote their text-processing capabilities more efficiently while coping with subsequent printed discourse.

At the final stage of the metacognitive strategy training, two reading comprehension texts (i.e., narrative, expository) were assigned to the participant EFL groups (control \& experimental). Indeed, the narrative and expository reading texts administered at the post-intervention phase are regarded as an effectual measure of whether the perceived effect of metacognitive training on the EFL learners' reading efficiency is noticeably fruitful. This was accompanied with the same 'self-report questionnaire' for revealing whether the treatment group had nurtured and put into play the focused metacognitive control strategies (e.g., planning, monitoring, evaluating) for generating effective sense of the academic written texts.

The data obtained through the 'self-report questionnaire' were computed through the Excel software Program (version 2007) to showcase the impact of metacognitive control training on the target subjects' use of metacognitive control strategies (e.g., planning, monitoring, evaluating) in text processing. This was reflected at the pre- and post-intervention level for both control and experimental groups. The reported metacognitive processes were numerically counted in percentile forms and turned into illustrative figures. This provides insights into whether the intervention can positively impact the EFL readers' strategic behaviour, especially among the treatment group.

\section{Results}

\subsection{Metacognitive Control Use among the Control Group in EFL Text Reading}

As manifestly reported in Figure 1 and Table 1, the metacognitive control strategies targeted in this study were not sufficiently implemented by the participating EFL learners in their way of conducting textual reading and constructing the contained meaning. The reached findings are summed up in the following figure and table. 


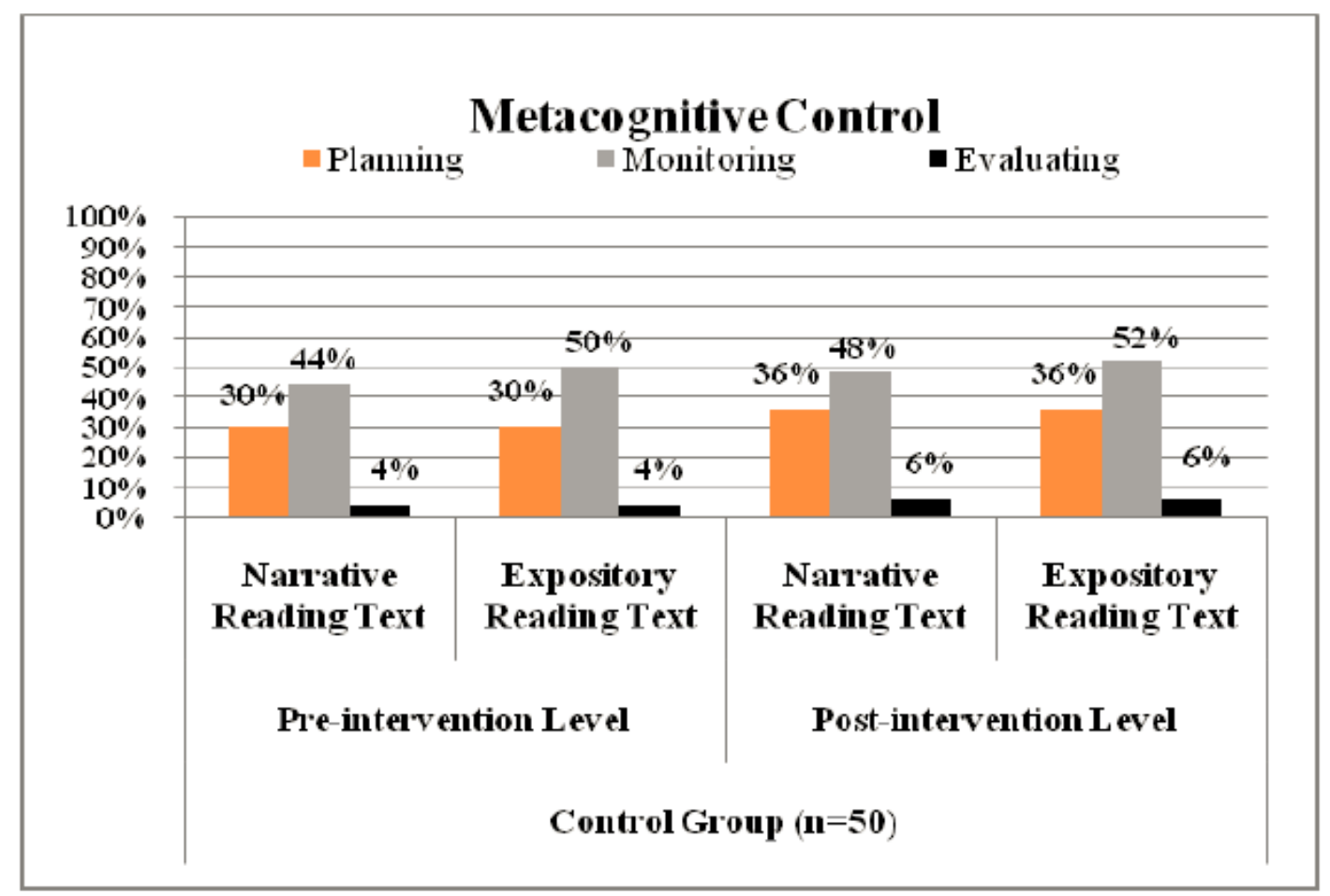

Figure 1. Control Group's Reliance on Metacognitive Control in Text Reading at Pre\&Post-intervention Levels

Table 1. Control Group's Reliance on Metacognitive Control during the Reading Process

\begin{tabular}{|c|c|c|c|c|c|c|c|}
\hline \multirow{3}{*}{ Intervention Stages } & & \multicolumn{6}{|c|}{ Control Group $(\mathbf{N}=50)$} \\
\hline & & \multicolumn{3}{|c|}{ Narrative Text } & \multicolumn{3}{|c|}{ Expository Text } \\
\hline & & $\mathbf{P}$. & M. & E. & P. & M. & E. \\
\hline \multirow[t]{2}{*}{ Pre-intervention } & $\mathbf{N}$ & 15 & 22 & 2 & 15 & 25 & 2 \\
\hline & $\%$ & $30 \%$ & $44 \%$ & $4 \%$ & $30 \%$ & $50 \%$ & $4 \%$ \\
\hline \multirow[t]{2}{*}{ Post-intervention } & $\mathbf{N}$ & 18 & 24 & 3 & 18 & 26 & 3 \\
\hline & $\%$ & $36 \%$ & $48 \%$ & $6 \%$ & $36 \%$ & $52 \%$ & $6 \%$ \\
\hline
\end{tabular}

The strategies of planning, monitoring and evaluating, as it is shown above (see Figure $1 \&$ Table 1), were not adequately depended on by the control subjects in their engagement in the reading process. Clearly, insufficiency in planning prior to being engaged in reading either the narrative or the expository text was a manifest fact among the EFL participants. At the pre-treatment stage, the control subjects did report planning their reading by setting goals for both the narrative and expository reading texts with a frequent use of $30 \%$. As to monitoring, the target subjects did read the narrative and expository text by exercising a certain measure of monitoring for comprehending the textual meaning with frequent occurrences of $44 \%$ and $50 \%$ respectively. Further, the strategy of evaluating was made use of in processing the 


\section{Macrothink}

assigned texts (i.e., narrative, expository) with a frequency of $4 \%$.

At the post-treatment stage, the subjects in the control group stated that they depended, to some extent, on planning with a percentage of $36 \%$ for the narrative and expository written texts. On the other hand, the participants in this group maintained that they had recourse to progress monitoring in analyzing the narrative and expository written discourse with percentages of $48 \%$ and $52 \%$ sequentially. However, the respondents did affirm that they resorted to evaluating, as a metacognitive strategic move, in reading both types of texts (i.e., narrative, expository) with a similar proportion of $6 \%$. Generally, it can be deduced that planning, monitoring and evaluating, as metacognitive control steps of accessing textual input, were not implemented by the EFL control group to a highly extended degree along the pre-and post-intervention continuum.

\subsection{Metacognitive Control Use among the Treatment Group in EFL Text Reading}

It is plausible, as Figure 2 and Table 2 display, that the large majority of the participants of the intervention group revealed a marked improvement at the level of directing and controlling their undertaken reading of the written discourse (i.e., narrative, expository) assigned to them throughout the pre-post-intervention stage. The results are manifested in the ensuing figure and table.

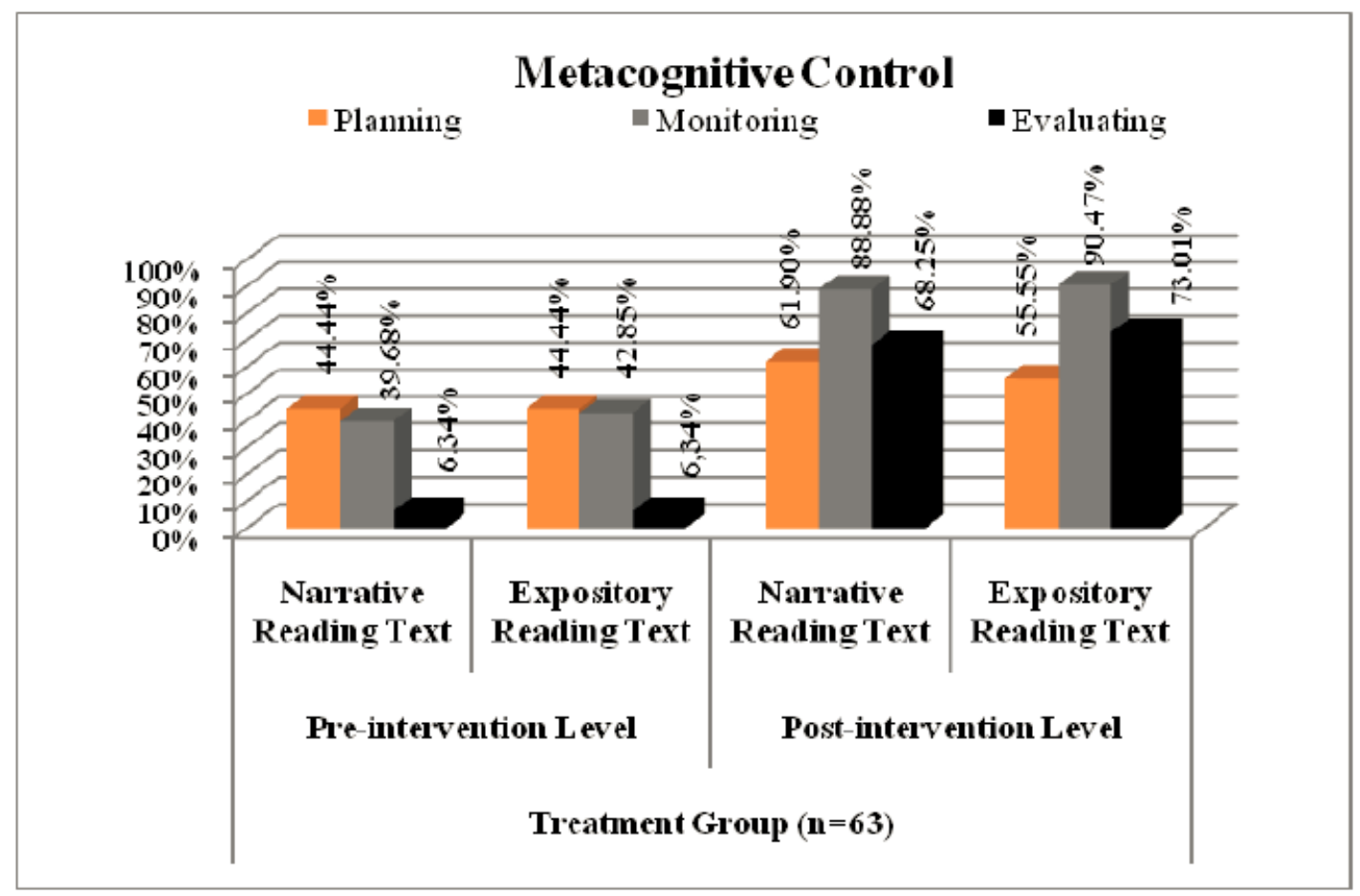

Figure 2. Treatment Group's Dependency on Metacognitive Control in Text Reading at Pre\& Post-intervention Levels 
Table 2. Treatment Group's Dependency on Metacognitive Control during the Reading Process

\begin{tabular}{|c|c|c|c|c|c|c|c|}
\hline \multirow{3}{*}{ Intervention Stages } & & \multicolumn{6}{|c|}{ Treatment Group $(\mathrm{N}=63)$} \\
\hline & & \multicolumn{3}{|c|}{ Narrative Text } & \multicolumn{3}{|c|}{ Expository Text } \\
\hline & & P. & M. & E. & P. & M. & E. \\
\hline \multirow[t]{2}{*}{ Pre-intervention } & $\mathbf{N}$ & 28 & 25 & 4 & 28 & 27 & 4 \\
\hline & $\%$ & $44.44 \%$ & $39.68 \%$ & $6.34 \%$ & $44.44 \%$ & $42.85 \%$ & $6.34 \%$ \\
\hline \multirow[t]{2}{*}{ Post-intervention } & $\mathbf{N}$ & 39 & 56 & 43 & 35 & 57 & 46 \\
\hline & $\%$ & $61.90 \%$ & $88.88 \%$ & $68.25 \%$ & $55.55 \%$ & $90.47 \%$ & $73.01 \%$ \\
\hline
\end{tabular}

According to the data reported above, it is manifest that at the pre-intervention level, the treatment group maintained that they had recourse to the technique of metacognitive planning for both kinds of texts, narrative and expository, with an occurrence of $44.44 \%$. For comprehension monitoring, the participants tended to depend upon this procedure with the intent of achieving understanding with frequencies of $39.68 \%$ and $42.85 \%$ in reading narrative and expository texts respectively. Additionally, the target EFL learners of this group evaluated their reading performance while reading the narrative and expository texts with a similar percentage of $6.34 \%$.

At the post-intervention level, the data show that a significant number of the learners in the treatment group did use the metacognitive control strategies of planning, monitoring and evaluating during reading the narrative as well as the expository text (see Figure $2 \&$ Table 2). The process of planning in an attempt to cope with the narrative and expository text content was executed with frequencies of $61.90 \%$ and $55.55 \%$ sequentially. Further, $88.88 \%$ of frequent occurrence represents the act monitoring the comprehension of the narrative text in order to attain adequate understanding, whereas $90.47 \%$ of frequent use of monitoring characterizes the procedure of monitoring the expository textual input. Also, evaluating the narrative and the expository text content was carried out among the target learners with percentages of $68.25 \%$ and $73.01 \%$ respectively. This reveals that the learners' increasing engagement in metacognitive control processes in coping with textual input can be underpinned by explicit training in these processes (e.g., planning, monitoring, evaluating).

\section{Discussion}

The present study made an inquiry into the practical value of the delivery of metacognitive control training in revamping EFL learners' strategic behaviour in textual processing. Thus, the study investigated how training in metacognitive self-regulation can serve both as a driving force for and potential predictor of the effective usage of planning, monitoring and evaluating that form the core, generic strategies in EFL reading in particular, and in reading in other languages (e.g., Arabic, French, Spanish, German, Russian) in general.

By drawing a comparison between the metacognitive control enacted before the intervention and the one called upon by both groups (control and treatment) after the intervention, it is evident that the treatment group developed and acquired a somewhat sophisticated kind of 
metacognitive monitoring and control deemed necessary for the construction of a coherent understanding of the textual input. Simply put, at the pre-treatment level, both groups seemed to be parallel, to an extent, in the use of metacognitive control which was rather somewhat undeveloped and limited. This confirms the first hypothesis stated in this study that Moroccan EFL university learners do not draw upon the key metacognitive reading strategies for processing written texts in an effective fashion. This finding is in concert with prior research studies (e.g., Meniado, 2016; Tabataba'ian \& Zabihi, 2011) showing insufficiency in the use of metacognitive reading strategies amongst learners. Yet, at post-treatment, the strategies underlying metacognitive control were characterized by sufficiency and effectiveness among the treatment group.

In effect, substantive improvement was exhibited in terms of planning, monitoring and evaluating strategies from pre- to post-intervention among the treatment group. Obviously, both concrete increase and manifest enhancement did mark the strategy-instructed participants' metacognitive control application. They gained sufficient knowledge of the basic strategic processes that are sturdily founded upon 'self-regulation' and 'self-control'. Therefore, the development of self-regulated and self-directed reading ability among the experimental group can be ascribed to the training they received throughout the semester-long period. This is, in a way, in utter concordance with the findings attained by previous research (e.g., Carell, et al., 1989; Boulware-Gooden, et al., 2007; Rupley, et al., 2009; Wichadee, 2011; Pei, 2014; Maftoon \& Tasnimi, 2014; Morshedian, et al., 2017). In this vein, the claim postulated in the second research hypothesis that strategy training can increase metacognitive control in textual reading among EFL learners can be positively confirmed. This view underscores that fostering a strategic, planned reading act among the EFL learners is predicated on metacognitive training which plays a great part in strengthening metacognitive control and monitoring pertaining to textual analysis and synthesis.

\section{Conclusion}

The study under investigation placed into perspective the premise that metacognitive control, which necessitates the reliance on high-order thinking skills on the part of the learners, can be deemed of paramount importance for the advancement of strategic reading behavior. This gives credence to the view that insufficient use of planning, monitoring and evaluating can be traceable to the lack of exposure to and training in metacognitive control as some researchers (e.g., Maftoon \& Tasnimi, 2014; Meniado, 2016; Morshedian, et al., 2017) claim. Hence, a considerable rethink is required in order that learners' reading potentiality can be advanced to a rather higher level.

In this context, the concerned academics and instructors are required to allocate a significant portion of the academic sessions to the explicit, purposeful teaching of metacognitive control as a promising gateway into refining the EFL learners' reading performance along the continuum of their studies at the university level. Within these parameters, metacognitive control training should be the practical focus of the Reading Comprehension Course in Moroccan tertiary education, especially in the first and second semesters. In essence, the inclusion of metacognitive control in the university curriculum can potentially predict an 
empowered, self-regulated reading act that facilitates academic success for learners in varying ways.

Overall, given the insightful nature of the findings reached in light of this study, few limitations can be brought forward. The main limitation encountered the target study was the issue of generalizability. Indeed, delimiting this quasi-experimental case study to the EFL learners studying at the Faculty of Letters and Humanities in Rabat suggests that EFL learners belonging to different Moroccan higher education institutions be the primary target of future academic research for warranting a global representativeness of the Moroccan EFL learners. Another limitation relates to the assumption whether instruction in metacognitive control can have a long-term or short-term effect on the target EFL learners. Put it simply, the findings of the study could be more consistent if the strategy-instructed group had been administered other post-intervention reading texts (i.e., narrative, expository) accompanied with another 'self-report questionnaire' in the subsequent semesters. This could ensure the permanency of metacognitive control use among the EFL subjects under focus and preclude the possibility that the influence of metacognitive training on the EFL learners' reading behavior is characterized by immediacy and transiency. Thus, prospective, relevant research studies should be directed towards this line of enquiry for further substantiation of the results.

\section{References}

Anani Sarab, M. R., \& Reihani, M. S. (2010). Cognitive and metacognitive strategy use and second language reading test performance: The case of Iranian intermediate EFL learners. Iranian Journal of Applied Linguistics, 13(2), 1-18. Retrieved from http://ijal.khu.ac.ir/article-1-36-en.html

André, M. D. A., \& Anderson, T. H. (1978-79). The development and evaluation of a self-questioning study technique. Reading Research Quarterly, 14(4), 605-623.

Baumann, J. F., Seifert-Kessel, N., \& Jones, L.A. (1992). Effect of think-aloud instruction on elementary students' comprehension monitoring abilities. Journal of Reading Behavior, 24, 143-172.https://doi.org/10.1080/10862969209547770

Bereiter, C., \& Bird, M. (1985).Use of thinking aloud in identification and teaching of reading comprehension strategies.Cognition and Instruction, 2(2), 131-156. https://doi.org/10.1207/s1532690xci0202_2

Boekaerts, M. (1999). Self-regulated learning: where we are today. International Journal of Educational Research, 31(6), 445-457. http://dx.doi.org/10.1016/S0883-0355(99)00014-2

Boulaware-Gooden, R., Carreker, S., Thornhill, A., \& Joshi, R. M. (2007). Instruction of metacognitive strategies enhances reading comprehension and vocabulary achievement of third-grade students. The Reading Teacher, 61(1), 70-77. http://dx.doi.org/10.1598/RT.61.1.7

Boyraz, S., \& Altinsoy, E. (2017).Metacognitive awareness of reading strategies in EFL context.International Journal of Language Academy, 5(5), 159-167.

Brown, A. L. (1980). Metacognitive development and reading. In R.J. Spiro, B. Bruce \& W.F. Brewer (Eds.), Theoretical Issues in Reading Comprehension (pp.453-479). Hillsdale, N.J.: 
Lawrence Erlbaum Associates.

Brown, A. L. (1981). Metacognition: The development of selective attention strategies for learning from texts. In M. L. Kamil (Ed.), Directions in Reading: Research and Instruction (pp.501-529). Washington, D.C.: National Reading Conference.

Butler, D. L., Cartier, S.C., Schnellert, L., Gagnon, F., \& Giammarino, M. (2011). Secondary students' self-regulated engagement in reading: Researching self-regulation as situated in context. Psychological Test and Assessment Modeling, 53(1), 73-105.

Carrell, P. L., Pharis, B. G., \& Liberto, J. C. (1989).Metacognitive strategy training for ESL reading.TESOL Quarterly, 23(4), 647-679. https://doi.org/10.2307/3587536

Casanave, C. P. (1988). Comprehension monitoring in ESL reading: A neglected essential. TESOL Quarterly, 22(2), 283-302. https://doi.org/10.2307/3586937

Cavanaugh, J. C., \& Perlmutter, M. (1982).Metamemory: A critical examination. Child Development, 53(1), 11-28. https://doi.org/10.2307/1129635

Dewitz, P., Carr, E. M., \& Patberg, J. P. (1987). Effects of inference training on comprehension and comprehension monitoring.Reading Research Quarterly, 22(1), 99-121.https://doi.org/10.2307/747723

Fernandez-Duque, D., Baird, J. A., \& Posner, M. I. (2000).Executive attention and metacognitive regulation. Consciousness and Cognition, 9(2), 288- 307. https://doi:10.1006/ccog.2000.0447

Flavell, J. H. (1971). First discussant's comments: What is memory development the development of? Human Development, 14(4), 272-278.https://doi.org/10.1159/000271221

Garner, R. (1987). Metacognition and Reading Comprehension. Norwood, New Jersey: Ablex Publishing Corporation.

Gaskins, I. W., Satlow, E., \& Pressley, M. (2007).Executive control of reading comprehension in the elementary school. In L. Meltzer (Ed.), Executive Function in Education: From Theory to Practice (pp.194-215). New York \& London: The Guilford Press.

Griffith, P. L., \& Ruan, J. (2005). What is metacognition and what should be its role in literacy instruction? In S. E. Israel, C. C., Block, K. L., Bauserman, and K. Kinnucan-Welsch (Eds.), Metacognition in Literacy Learning: Theory, Assessment, Instruction, and Professional Development (pp.3-18). New Jersey: Lawrence Erlbaum Associates.

Hall, C. S. (2016). Inference instruction for struggling readers: A synthesis of intervention research. Educational Psychology Review, 28(1), 1-22. https://doi.org/10.1007/s10648-014-9295-X

Hill, J. R., \& Hannafin, M. J. (1997). Cognitive strategies and learning from the world wide web. Educational Technology Research and Development, 45(4), 37-64. https://doi.org/10.1007/BF02299682

Hogan, M. J., Dwyer, C. P., Harney, O. M., Noone, C., \& Conway, R. J. (2015). Metacognitive skill development and applied systems science: A framework of metacognitive 
skills, self-regulatory functions and real-world applications. In A. Peña-Ayala (Ed.), Metacognition: Fundaments, Applications, and Trends (pp.75-106). Berlin: Springer.

Janssen, T. (2002). Instruction in self-questioning as a literary reading strategy: An exploration of empirical research. Educational Studies in Language and Literature, 2(2), 95-120. http://dx.doi.org/10.1023/A:1020855401075

Jiménez, R. T., García, G. E., \& Pearson, P. D. (1996). The reading strategies of bilingual Latina/o students who are successful English readers: Opportunities and obstacles. Reading Research Quarterly, 31(1), 90-112.https://doi.org/10.1598/RRQ.31.1.5

Johnson, L., Graham, S., \& Harris, K. R. (1997). The effects of goal setting and self-instruction on learning a reading comprehension strategy: A study of students with learning disabilities. Journal of Learning Disablities, 30(1), 80-91. https://doi.org/10.1177/002221949703000107

Jones, B. F., Palinscar, A. S., Ogle D. S., \& Carr, E. G. (1987). Strategic Teaching and Learning:Cognitive Instruction in the Content Areas. Alexandra: Association for Supervision and Curriculum Development.

Kern, R. G. (1989). Second language reading strategy instruction: Its effects on comprehension and word inference ability. The Modern Language Journal, 73(ii), 135-149. https://doi.org/10.1111/j.1540-4781.1989.tb02535.x

Lauterbach, S. L., \& Bender, W. N. (1995). Cognitive strategy instruction for reading comprehension: A success for high school freshmen. The High School Journal, 79(1), 58-64. Retrieved from https://www.jstor.org/stable/40364744

Lawrence, L. J. (2007). Cognitive and metacognitive reading strategies revisited: Implications for instruction. The Reading Matrix, 7(3), 55-71.

Li, F. (2010).A study of English reading strategies used by senior middle school students.Asian Social Science, 6(10), 184-192.

Maftoon, P., \& Tasnimi, M. (2014).Using self-regulation to enhance EFL learners' reading comprehension.Journal of Language Teaching and Research, 5(4), 844-855. https://doi:10.4304/j1tr.5.4.844-855

Meniado, J.C. (2016). Metacognitive reading strategies, motivation, and reading comprehension performance of Saudi EFL students.English Language Teaching, 9(3), 117-129. http://dx.doi.org/10.5539/elt.v9n3p117

Morshedian, M., Hemmati, F., \& Sotoudehnama, E. (2017). Training EFL learners in self-regulation of reading: Implementing an SRL model. Reading and Writing Quarterly, 33(3), 290-303. https://doi.org/10.1080/10573569.2016.1213147

Msaddek, M. (2016).The effect of metacognitive strategy instruction on Moroccan EFL learners' strategy use and reading achievement.Arab World English Journal (AWEJ), 7(3), 271-285. https://dx.doi.org/10.24093/awej/vol7no3.21

Nietfeld, J. L., Cao, L., \& Osborne, J. W. (2005). Metacognitive monitoring accuracy and 
student performance in the post-secondary classroom.The Journal of ExperimentalEducation, 74(1), 7-28. Retrieved from https://www.jstor.org/stable/20157410?seq=1

Paris, S. G., \& Paris, A. H. (2001). Classroom applications of research on self-regulated $\begin{array}{lllll}\text { learning. } & \text { Educational } & \text { Psychologist, } & 36 & \text { (2), }\end{array}$ https://doi.org/10.1207/S15326985EP3602_4

Paris, S. G., Wixson, K. K., \& Palincsar, A. C. (1986). Instructional approaches to reading comprehension. Review of Research in Education, 13/ 91-128. https://doi.org/10.3102/0091732X013001091

Pei, L. (2014). Does metacognitive strategy instruction indeed improve Chinese EFL learners' reading comprehension performance and metacognitive awareness? Journal of Language Teaching and Research, 5(5), 1147-1152.

Pressley, M. (2000). What should comprehension instruction be the instruction of? In M.L. Kamil, P. B. Mosenthal, P.D. Pearson, \& R. Barr (Eds.), Handbook of Reading Research, Volume 3 (pp. 545-561). Mahwah NJ: Lawrence Erlbaum.

Rahimi, M., Abedi, S. (2015). The role of metacognitive awareness of listening strategies in listening proficiency: The case of language learners with different levels of academic self-regulation. In A. Peña-Ayala (Ed.), Metacognition: Fundaments, Applications, and Trends (pp.169-192). Berlin: Springer.

Rahmani, M., \& Sadeghi, K. (2011).Effects of note taking training on reading comprehension and recall.The Reading Matrix, 11(2), 116-128.

Roohani, A., \& Asiabani, S. (2015). Effects of self-regulated strategy development on EFL learners' reading comprehension and metacognition.Journal of Language Studies, 15(3), $31-52$.

Rupley, W. M., Blair, T. R., \& Nicholas, W. D. (2009). Effective reading instruction forstruggling readers: The role of direct/explicit teaching. Reading and Writing Quarterly,25, (2/3), 125-138.https://doi.org/10.1080/10573560802683523

Schmitt, M. C., \& Newby, T. J. (1986). Metacognition: Relevance to instructional design. Journal of Instructional Development, 9(4), 29-33. https://doi.org/10.1007/BF02908316

Schraw, G., \& Moshman, D. (1995). Metacognitive theories. Educational Psychology Review, 7(4), 351-371. https://doi.org/10.1007/BF02212307

Shellings, G. (2011). Applying learning strategy questionnaires: Problems and possibilities.Research Institute Child Development and Education, 6, 91-109. https://doi.org/10.1007/s11409-011-9069-5

Shimamura, A. P. (2000). Toward a cognitive neuroscience of metacognition.Consciousness and Cognition, 9(2), 313-323. https://doi.org/10.1006/ccog.2000.0450

Short, E.J., \& Ryan, E. B. (1984). Metacognitive differences between skilled and less skilled readers: Remediating deficits through story grammar and attribution training. Journal of Educational Psychology, 76 (2), 225-235. https://doi.org/10.1037/0022-0663.76.2.225 


\section{Macrothink}

International Journal of English Language Education

ISSN 2325-0887

2021, Vol. 9, No. 1

Singer, H., \& Donlan, D. (1982). Active comprehension: Problem-solving schema with question generation for comprehension of complex short stories. Reading Research Quarterly, 17(2), 166-186.https://doi.org/10.2307/747482

Smith, R. J., \& Dauer, V. L. (1984). A comprehension-monitoring strategy for reading content area materials. Journal of Reading, 28(2), 144-147.

Sternberg, R. J. (1984). Mechanisms of cognitive development: A componential approach. In R. J. Sternberg (Ed.), Mechanisms of Cognitive Development (pp.163-186). New York: W.H. Freeman and Company.

Tabataba'ian, M. S., \& Zabihi, R. (2011). Strategies used by four Iranian EFL learners in reading ESP and GPE texts: A think-aloud case study. World Journal of English Language, l(1), 53-62.https://doi.org/10.5430/wjel.v1n1p53

Tonks, S. M., \& Taboada, A. (2011).Developing self-regulated readers through instruction for reading engagement.In B. J. Zimmerman \& D. H. Schunk (Eds.), Handbook of self-regulation of learning and performance (pp. 173-186). New York: Routledge.

Wenden, A. (1991). Learner Strategies for Learner Autonomy. London: Prentice-Hall International.

Wichadee, S. (2011).Developing the self-directed learning instructional model to enhance English reading ability and self-directed learning of undergraduate students.Journal of College Teaching \& Learning, 8(12), 43-52.https://doi.org/10.19030/tlc.v8i12.6620

Zimmerman, B. J. (1990). Self-regulated learning and academic achievement: An overview. Educational Psychologist, 25(1), 3-17. http://dx.doi.org/10.1207/s15326985ep2501_2

\section{Copyright Disclaimer}

Copyright for this article is retained by the author(s), with first publication rights granted to the journal.

This is an open-access article distributed under the terms and conditions of the Creative Commons Attribution license (http://creativecommons.org/licenses/by/3.0/). 